\title{
Brief Communication: The Effects of Disuse on the Mechanical Properties of Bone: What Unloading Tells Us About the Adaptive Nature of Skeletal Tissue
}

\author{
Stephen H. Schlecht, ${ }^{1 *}$ Deborrah C. Pinto, ${ }^{2}$ Amanda M. Agnew, ${ }^{3,4}$ and Sam D. Stout ${ }^{3}$ \\ ${ }^{1}$ Department of Orthopaedic Surgery, University of Michigan, Ann Arbor, MI 48109 \\ ${ }^{2}$ Harris County Institute of Forensic Sciences, Houston, TX 77054 \\ ${ }^{3}$ Department of Anthropology, The Ohio State University, Columbus, OH 43210 \\ ${ }^{4}$ Division of Anatomy, The Ohio State University College of Medicine, Columbus OH 43210
}

\begin{abstract}
KEY WORDS immobilization; disuse osteoporosis; osteon population density; osteon area; cross-sectional geometry
\end{abstract}

\begin{abstract}
The intricate link between load environment and skeletal health is exemplified by the severe osteopenia that accompanies prolonged periods of immobilization, frequently referred to as disuse osteoporosis. Investigating the effects disuse has on the structural properties of bone provides a unique opportunity to better understand how mechanical loads influence the adaptation and maintenance of skeletal tissue. Here, we report results from an examination of multiple indicators of bone metabolism (e.g., mean osteon density, mean osteon size, bone mass, and bone area distribution) within the major long bones of individuals with distinct activity level differences. Results are based on a sample comprising two subjects that suffered from long-term quadriplegia and 28 individuals of comparable age that had full limb mobility. Although limited in sample size, our findings suggest bones associated with long-term disuse have lower osteon
\end{abstract}

The importance of mechanical loading in bone metabolism is well established. The crucial role it plays in skeletal health is aptly illustrated by the severe osteopenia that accompanies prolonged periods of immobilization, commonly referred to as disuse osteoporosis. Examining the effects unloading has on the structural properties of bone provides a unique opportunity to better understand the role mechanical loading plays in the adaptation and maintenance of this dynamic tissue. This study reports the results of a comprehensive macro- and microscopic analysis of all major long bones belonging to two individuals that experienced long-term immobilization, and a broad range of comparable individuals demonstrating normal mobility levels.

Long-term immobilization, resulting in a profound reduction of mechanical loading, dramatically affects bone turnover rates and compromises the structural and functional integrity of bone (Uhthoff and Jaworski, 1978; Jaworski et al., 1980; Stout, 1982; Dehority et al., 1999; Giangregorio and Blimkie, 2002). Prolonged skeletal disuse results in decreased bone mass and subsequently disuse osteoporosis. There are various circumstances of unloading that demonstrate both temporary and permanent osteoporotic conditions, including extended bed rest (Bloomfield, 1997), hypogravity (i.e., space flight) (Globus and Morey-Holton, 2009; Bloomfield, 2010), myopathies, denervating pathologies (Wakley et al., 1992), and spinal cord sectioning (Eser et al., 2004; Qin et al., 2010). densities and larger osteon areas compared to individuals of normal mobility, reflecting dramatically lower remodeling rates potentially related to reduced strain levels. Moreover, immobilized skeletal elements demonstrate a reduced percentage of cortical area present resulting from endosteal resorption. Differences between mobility groups in the percentage of cortical area present and bone distribution of all skeletal elements, suggests bone modeling activity is negligible in the unloaded adult skeleton. Additional histomorphometric comparisons reveal potential intraskeletal differences in bone turnover rates suggesting remodeling rates are highest within the humeri and femora. Addition of more immobilized individuals in the future will allow for quantitative statistical analyses and greater consideration of human variation within and between individuals. Am J Phys Anthropol 149:599-605, 2012. @2012 Wiley Periodicals, Inc.

Currently, a mechanism based on threshold levels established during skeletal growth and development (Carter, 1984; Lanyon, 1984; Frost, 1987), commonly referred to as the mechanostat, provides one explanation for why unloading results in such dramatic bone loss. This mechanism envisions a negative feedback loop wherein signals due to disproportion in mechanical loading are detected and corrected for via a series of set points delineating a normal threshold level. Strain outside this defined threshold range initiates a modeling or remodeling response to adjust bone strength accordingly. Strain above a higher remodeling threshold activates modeling to increase periosteal apposition, and remodeling to replace fatigue-damaged bone; collectively strengthening and maintaining bone. Strain below a lower remodeling threshold activates remodeling to decrease bone mass and subsequently increase the strain level.

\footnotetext{
*Correspondence to: Dr. Stephen Schlecht, Department of Orthopaedic Surgery, University of Michigan, 2148 Biomedical Science Research Building, 109 Zina Pitcher Place, Ann Arbor, MI, 48109. E-mail: sschlech@med.umich.edu
}

Received 16 April 2012; accepted 24 August 2012

DOI 10.1002/ajpa.22150

Published online 19 October 2012 in Wiley Online Library (wileyonlinelibrary.com). 
Disuse-driven remodeling is characterized by the coupled, coordinated action of osteoclasts and osteoblasts to remove and replace bone from either the endosteal and intracortical surfaces or both. The result of each remodeling event is the formation of a new bone structural unit, also known as a secondary osteon. Remodeling in any form results in a net bone loss as a vascular space, or Haversian canal, is an essential osteonal component for fluid and nutrient movement. Disuse-remodeling demonstrates an even greater net loss as osteoclasts become uncoupled from osteoblasts (Alexandre and Vico, 2011), resulting in large resorption spaces as substantially more bone is removed than is replaced. Therefore, disuse-remodeling results in marrow expansion as the endosteum is slowly resorbed via coalescing porous spaces that effectively trabecularize the cortical matrix (Burr, 2010; Zebaze et al., 2010), reducing the metabolic expense of unnecessary bone tissue.

In addition to strain level, increased osteocyte apoptosis resulting from diminished intramedullary fluid pressure (Turner, 1999), may also be a factor elevating remodeling events following disuse. Additionally, recent research on the role of sclerostin protein, a known bone forming inhibitor produced by the SOST gene, has found increased SOST mRNA levels in rodents subjected to hindlimb disuse (Robling et al., 2008). Sclerostin is presumed to reduce proliferation while elevating the frequency of cellular apoptosis (Sutherland et al., 2004).

Previous studies largely based on animal models have confirmed the overall effect immobilization has on bone mineral density (see Gross et al., 2010 for a review). However, many of these studies lack significant periods of disuse or histomorphometric investigation, limiting understanding of remodeling activity associated with permanent, long-standing disuse. Additionally, few studies have assessed the degree of intraskeletal variability in remodeling rates between skeletal elements. The goal of this study is to examine multiple indicators of bone metabolism within a sample of individuals with distinct activity level differences, subjects that suffered from long-term quadriplegia and those that had full limb mobility. This provides a unique investigation into remodeling associated with skeletal unloading rather than loading, allowing us to contribute to both established and recently proposed hypotheses of remodeling behaviors reflective of various loading regimes.

\section{MATERIALS AND METHODS Sample}

This study incorporated two Caucasian quadriplegic females that demonstrated complete limb immobility for most of their adult lives. Individual A was a 54-year-old woman suffering paralysis from bulbar poliomyelitis for $\sim 26$ years, with no recovery of muscle strength. This subject was acquired from the Washington University-St. Louis, Department of Anatomy dissecting room. Individual B was a 70-year-old woman who suffered a cervical spinal cord section in an automobile accident, resulting in paralysis for more than 50 years. This subject was acquired through the Division of Anatomy Body Donation Program at The Ohio State University. For both individuals, midshaft cross-sections were obtained from all major long bones of the left and right limbs including the humerus, radius, ulna, femur, tibia, and fibula of the upper and lower limbs.
The comparative sample representing normal mobility consists of 28 individuals, 15 males and 13 females, of Caucasian and African-American descent. In the interest of matching the age of the two immobilized women, the majority of the non-immobilized subjects are between the ages of $50-60$ years and $65-75$ years, with a total age range of 34-82 years for the entire sample. Bone samples for all individuals included in the non-immobilized group were acquired from the Washington University School of Medicine (St. Louis, MO) and the University of Missouri Medical School (Columbia, MO) between 1976 and1980 by S.D.S. and demonstrated no known pathologies or therapeutic regimens that may have impacted bone remodeling rates. For all individuals, midshaft cross-sections were selectively obtained from various long bones of the right upper and lower limbs, collectively including the humerus $(n=25)$, radius $(n=21)$, ulna $(n=21)$, femur $(n=18)$, tibia $(n=24)$, and fibula $(n=20)$.

\section{Histological methods}

All midshaft samples were prepared for histomorphometric and cross-sectional geometric analysis. Each midshaft section was vacuum embedded in an appropriate epoxy medium, (e.g., Epo-Thin ${ }^{\mathrm{TM}}$, Buehler, Lake Bluff, IL) to safeguard structural integrity during cutting and grinding and to eliminate air bubbles that may obscure the delineation of microscopic structures. After allowing the bone blocks to set, transverse sections $1 \mathrm{~mm}$ in thickness were removed using an IsoMet petrographic precision saw equipped with a diamond wafering blade (Buehler). Resulting wafers were then ground to a thickness of approximately $60-80 \mu \mathrm{m}$ using a variable speed manual grinder (Buehler) to achieve a translucency appropriate for transmitted-light microscopy. After this, thin sections were cleaned in acetone, cleared with xylene, mounted, and cover slipped to microscopic slides with Permount ${ }^{\mathrm{TM}}$.

Prepared slides were read using an Olympus BX51 transmitted-light microscope (Olympus Optical Co., Tokyo, Japan) fitted with a Mertz eyepiece reticule and polarizing filter. The Mertz grid superimposed on the thin section in view delineates the sampling field, or unit of area quantified. Sampling of all specimens consisted of reading two adjacent parallel columns extending from the periosteum to the endosteum along the anterioposterior and mediolateral axes at $100 \times$ magnification. This is a practical method for accurately predicting total osteon density while accounting for intracortical variation in remodeling activity (Iwaniec, 1997; Robling and Stout, 2008; Schlecht, 2012). For all cross-sections, the following histomorphometric variables were quantified.

1. Total cortical area of bone sampled per cross-section (Sa.Ar)

2. Total number of intact secondary osteons (N.On) in number $/ \mathrm{mm}^{2}$ : intact secondary osteons are those exhibiting a Haversian canal that is at least $90 \%$ complete and more than half of the osteon area falls within the sampling field:

$$
\text { N.On }=\text { Total number of intact osteons/Sa.Ar. }
$$

3. Total number of fragmentary osteons (N.On.Fg) in number $/ \mathrm{mm}^{2}$ : fragmentary secondary osteons are 
those exhibiting only a fraction of the original lamellar area and more than $10 \%$ removal of the Haversian canal via subsequent remodeling events. Additionally, more than half of the fragment's area falls within the sampling field:

\section{N.On.Fg $=$ Total number of fragmentary Osteons/Sa.Ar.}

4. Osteon population density (OPD) in number $/ \mathrm{mm}^{2}$ : the sum of N.On and N.On.Fg:

$$
\mathrm{OPD}=\mathrm{N} . \mathrm{On}+\mathrm{N} \cdot \mathrm{On} \cdot \mathrm{Fg} .
$$

Mean area of complete osteons (On.Ar) within the sampling field was also quantified. Complete osteons are those with intact reversal cement lines and a near circular Haversian canal, which minimizes the chance of measuring a tangentially sectioned osteon. All delineated osteons were photographed at $400 \times$ magnification using a mounted Insight QE live image camera (SPOT Imaging Solutions, Sterling Heights, MI). Using ImageJ freeware $(\mathrm{NIH})$, photomicrographs were digitally displayed and the reversal cement line of each osteon was manually traced for digital calculation of osteon area. On.Ar, calculated from at least 25 osteons per cross-section, was then quantified. A high magnification of $400 \times$ was chosen to reduce potential error when outlining the selected osteon, because minor deviations from the actual cement line are likely miniscule at this level.

In addition to the computed histomorphometrics, various cross-sectional geometric variables were quantified to assess bone mass and cortical bone distribution differences of the long bones. Each thin section was scanned on a flatbed scanner and geometric variables were computed using ImageJ (NIH), along with a custom macro (Momentmacro.J; www.hopkinsmedicine.org/fae/mmacro.htm) that calculates cross-sectional mechanical properties, second moments of area, and section moduli. Mechanical data quantified directly from each crosssection include total area (Tt.Ar), cortical area (Ct.Ar), and the second moments of area $I_{\min }$ and $I_{\max }$. From these observed values, the percentage of cortical area present (\% Ct.Ar) and the polar second moment of area (J) was calculated. The percentage of Ct.Ar is the ratio of Ct.Ar/Tt.Ar, reflecting relative bone volume. $J$ is the sum of $I_{\min }$ and $I_{\max }$ and is proportional to the torsional and average bending rigidity of bone, reflecting bone distribution responses to loading. Body mass and bone length are unknown for individuals comprising the sample, thus body size standardization of the geometric variables was not carried out. Therefore, only gross differences in bone volume and distribution are assessed between and within individuals and no inferences are made concerning the relative strength of the bone.

\section{Statistical methods}

The goal of this study is to describe various indicators of bone metabolism in individuals that experienced prolonged disuse, and to assess intraskeletal variability in the long bones of the upper and lower limbs associated with unloading. Statistical analyses to evaluate this relationship were accomplished using Minitab 16.1.1 (Minitab, State College, PA) software.

Normality tests of OPD, On.Ar, Ct.Ar, and $J$ demonstrated that the data were non-normal and were therefore logarithmically transformed to achieve a near-normal dis- tribution. Untransformed, median values for each of the sample subgroups are provided in Table 1 . To evaluate differences between the four indicators of bone metabolism in relation to varying load regimes, individual skeletal elements of the immobilized and non-immobilized subjects were qualitatively compared using mean plots. Means for the non-immobilized individuals were plotted with $95 \%$ confidence intervals, with values of the two immobilized individuals separately plotted to determine where they fall in relation to the mobile group. Assessment of intraskeletal differences included both an analysis of the two quadriplegics compared to all non-immobilized individuals, and to only those non-immobilized individuals of similar age. Therefore, in age-matched comparisons, the 54- and 70-year-old quadriplegics were compared to non-immobilized samples with age ranges of 50-60 years and 65-75 years, respectively.

\section{RESULTS AND DISCUSSION}

Figure 1 presents mean plots of the four indicators of bone metabolism between all mobile individuals included in the study and each of the quadriplegic females. Compared to the individuals with normal mobility, the 54-year-old immobile female demonstrates lower OPD values outside the $95 \%$ confidence intervals for all skeletal elements (Fig. 1a). This is most likely a result of both reduced mechanical stimuli and cortical thinning resulting from endosteal resorption, as discussed below. The effects of reduced mechanical loading are further supported in the plot for On.Ar, which reveals that the long bones typically subjected to the greatest load (i.e., humeri, radii, femora, and tibiae) are larger in size within the immobile limbs compared to those with normal mobility (Fig. 1b). The fibulae and ulnae demonstrate osteon sizes well within the range of their mobile counterparts, though greater than the mean, reflecting their lesser role in bearing applied loads compared to their more prominent forelimb partners (i.e., the radius and tibia) (Wang et al., 1996; Birkbeck et al., 1997). In terms of cross-sectional geometry, both $J$ (Fig. 1c) and \% Ct.Ar (Fig. 1d) are generally lower than the 95\% confidence interval of individuals with normal mobility, which most likely reflects increased endosteal resorption and/or reduced bone formation. However, as demonstrated in the plot for On.Ar, the fibula and ulna appear to be less affected as \% Ct.Ar for these skeletal elements is clearly within the normal range.

When considering the plots for the 70-year-old quadriplegic female, most of the trends observed in the 54year-old are similar. Some important contrasts are observable in respects to OPD (Fig. 1a) wherein several of the immobile long bones-particularly the fibulae, radii, and tibiae-demonstrate values well within the $95 \%$ confidence intervals of the normally mobile individuals. This rise in OPD compared to the 54-year old may reflect estrogen depletion characteristic of a post-menopausal state (Troen, 2003; Kearns et al., 2008), wherein osteoclast proliferation is less inhibited, resulting in elevated bone turnover rates. Additionally, in terms of \% Ct.Ar, the fibulae and ulnae demonstrate endosteal resorption well outside 95\% confidence intervals compared to that observed in the younger 54-year-old quadriplegic (Fig. 1c).

With regards to mean distribution between the respective immobilized individuals and their age-matched groups of mobile individuals, trends are consistent with 
TABLE 1. Untransformed, median data for all subgroups included in this sample

\begin{tabular}{|c|c|c|c|c|c|c|c|}
\hline Sample group & Bone & OPD & On.Ar & Tt.Ar & Ct.Ar & $I_{\max }$ & $I_{\min }$ \\
\hline \multirow{6}{*}{$\begin{array}{l}\text { All mobile individuals } \\
\qquad(n=15 \text { males, } 13 \text { females })\end{array}$} & Femur & 23.56 & 0.0346 & 548.10 & 351.40 & 24,147 & 18,222 \\
\hline & Fibula & 18.62 & 0.0408 & 110.62 & 79.40 & 1,433 & 695 \\
\hline & Humerus & 23.00 & 0.0382 & 304.30 & 196.10 & 7,204 & 4,800 \\
\hline & Radius & 20.78 & 0.0378 & 107.06 & 88.99 & 1,158 & 782 \\
\hline & Tibia & 18.70 & 0.0355 & 471.20 & 288.80 & 23,261 & 9,476 \\
\hline & Ulna & 18.77 & 0.0408 & 117.50 & 83.08 & 1,653 & 803 \\
\hline \multirow{6}{*}{$\begin{array}{l}\text { Mobile 50-60-year-olds } \\
\quad(n=6 \text { males, } 5 \text { females })\end{array}$} & Femur & 23.37 & 0.0428 & 511.40 & 367.50 & 23,383 & 16,167 \\
\hline & Fibula & 18.41 & 0.0399 & 108.75 & 83.50 & 1,396 & 696 \\
\hline & Humerus & 20.65 & 0.0383 & 310.60 & 219.80 & 8,147 & 6,134 \\
\hline & Radius & 20.29 & 0.0370 & 116.34 & 97.92 & 1,403 & 862 \\
\hline & Tibia & 16.69 & 0.0423 & 473.00 & 322.50 & 24,217 & 10,641 \\
\hline & Ulna & 18.77 & 0.0453 & 145.70 & 116.37 & 2,388 & 1,276 \\
\hline \multirow{6}{*}{$\begin{array}{l}\text { Mobile } 65-75 \text {-year olds } \\
\qquad(n=6 \text { males, } 2 \text { females })\end{array}$} & Femur & 27.84 & 0.0289 & 586.70 & 337.10 & 24,965 & 20,444 \\
\hline & Fibula & 18.84 & 0.0328 & 112.50 & 62.00 & 1,186 & 630 \\
\hline & Humerus & 30.77 & 0.0321 & 285.50 & 172.90 & 6,374 & 4,270 \\
\hline & Radius & 23.25 & 0.0354 & 133.20 & 83.40 & 1,768 & 951 \\
\hline & Tibia & 24.23 & 0.0297 & 501.90 & 288.00 & 23,578 & 13,665 \\
\hline & Ulna & 20.86 & 0.0352 & 100.30 & 71.60 & 1,192 & 543 \\
\hline \multirow[t]{6}{*}{ Immobile 54-year old } & Femur & 11.79 & 0.0486 & 468.19 & 149.48 & 10,282 & 8,707 \\
\hline & Fibula & 9.43 & 0.0431 & 77.92 & 51.38 & 691 & 340 \\
\hline & Humerus & 15.22 & 0.0517 & 247.96 & 90.70 & 3,278 & 2,530 \\
\hline & Radius & 15.56 & 0.0428 & 107.61 & 59.44 & 1,227 & 486 \\
\hline & Tibia & 14.17 & 0.0451 & 390.67 & 194.87 & 13,110 & 6,571 \\
\hline & Ulna & 12.83 & 0.0508 & 104.21 & 75.30 & 1,113 & 625 \\
\hline \multirow{6}{*}{ Immobile 70 -year old } & Femur & 16.31 & 0.0494 & 429.15 & 123.65 & 7,540 & 6,278 \\
\hline & Fibula & 20.04 & 0.0497 & 86.91 & 25.69 & 414 & 222 \\
\hline & Humerus & 18.80 & 0.0525 & 188.61 & 58.24 & 1,764 & 1,272 \\
\hline & Radius & 19.07 & 0.0429 & 81.60 & 32.96 & 432 & 289 \\
\hline & Tibia & 21.97 & 0.0410 & 363.40 & 61.56 & 4,146 & 2,528 \\
\hline & Ulna & 14.48 & 0.0452 & 80.22 & 36.59 & 449 & 317 \\
\hline
\end{tabular}
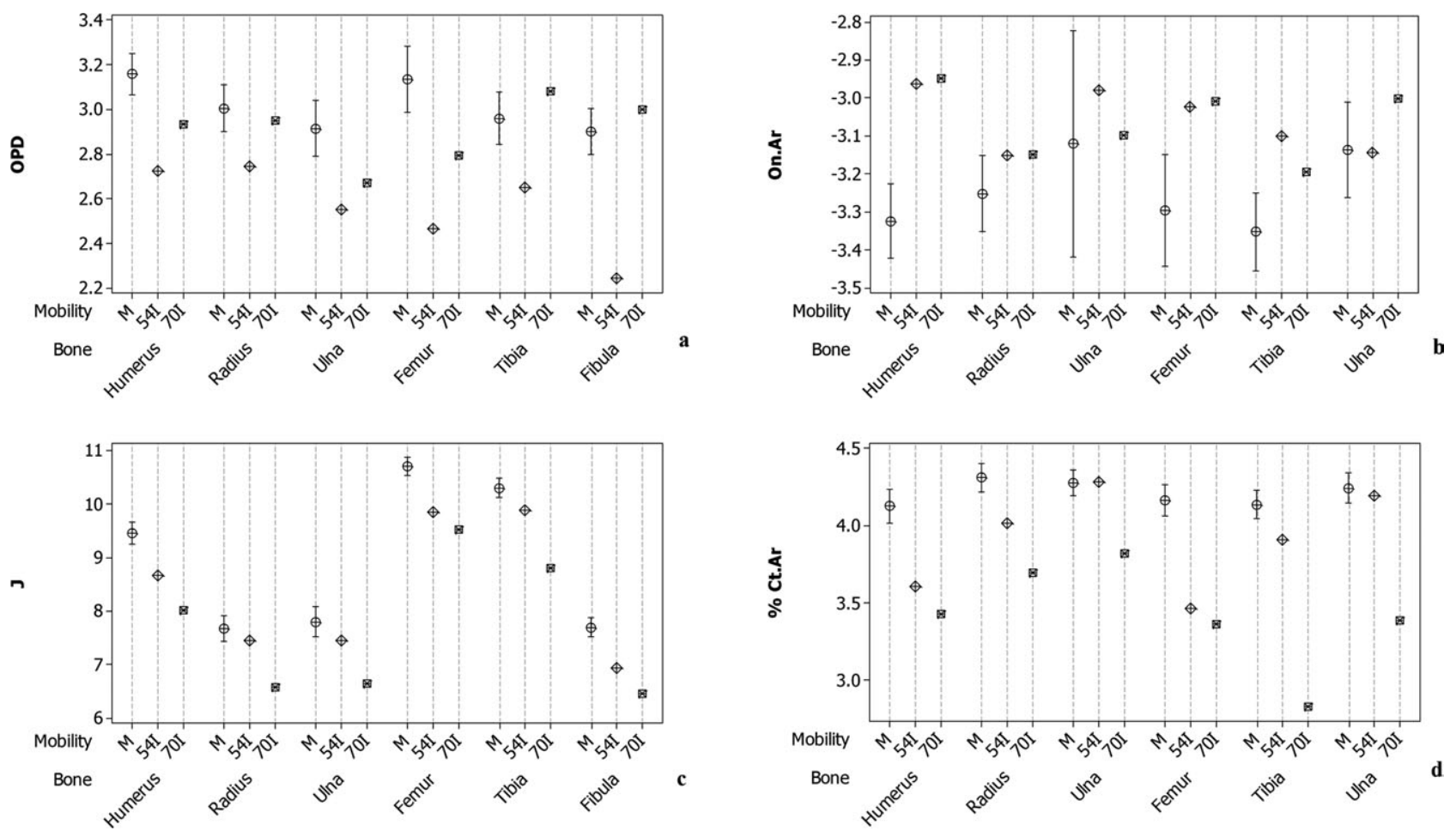

Fig. 1. Mean plots with $95 \%$ confidence intervals for all mobile individuals compared to the means for each immobile individual. (a) OPD, (b) On.Ar, (c) J, and (d) \% Ct.Ar. M, mobile; 54I, 54-year-old immobile; 70I, 70-year-old immobile.

those noted above (Figs. 2 and 3). The primary difference is the increased 95\% confidence intervals of the mobile individuals due to decreased sample size, which minimally dilutes differences observed when all mobile indi- viduals are considered. For all four indicators of bone metabolism, the femora and humeri appear to be the most consistently affected skeletal elements with respect to long term disuse. 

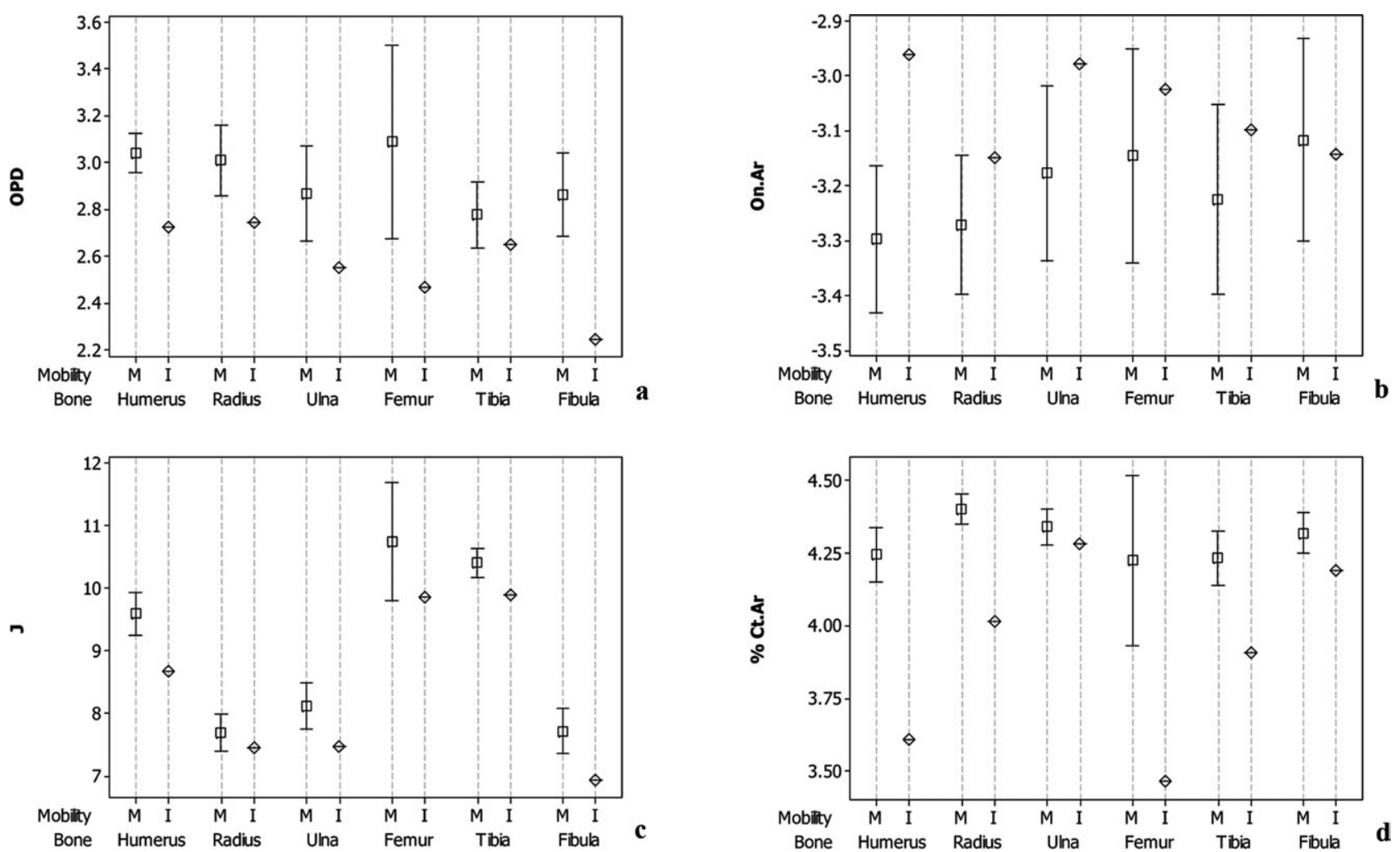

Fig. 2. Mean plots with $95 \%$ confidence intervals for 50-60-year-old mobile individuals compared to the means for the immobile 54-year-old female. M, mobile; I, immobile.
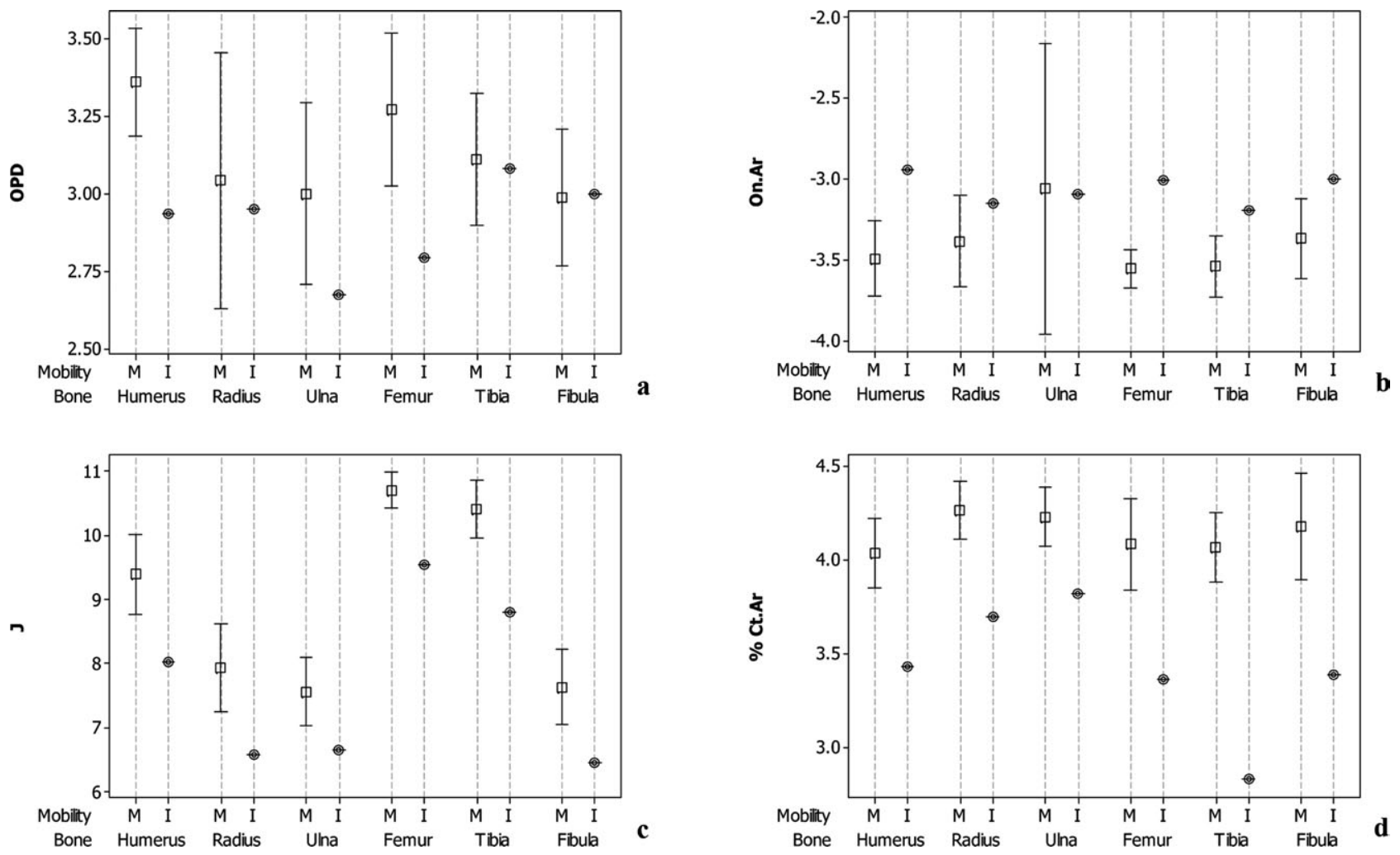

Fig. 3. Mean plots with $95 \%$ confidence intervals for 65-75-year-old mobile individuals compared to the means for the immobile 70-year-old female. M, mobile; I, immobile. 
In addition to the potential histomorphometric differences between mobility groups, visual observations between OPD and On.Ar of all long bones appear to be negatively related. This presumed relationship compliments Frost's (1990) hypothesis, which postulates that as osteon density increases osteon size decreases. Additionally, the data are in agreement with previous histomorphometric investigations by Skedros et al. (2001) and van Oers et al. (2008), suggesting both experimentally and computationally that bone resorption is inhibited by strain-generated osteocyte signals. According to these studies, osteoclasts are inhibited in mechanically loaded bone, resulting in smaller osteon diameters in cortical regions subjected to high strain magnitudes. Presence of small, densely packed osteons in cortical regions experiencing strains above the normal remodeling threshold is presumably advantageous as the cement lines of secondary osteons are believed to assist in arresting the propagation of microcracks, decreasing the probability of catastrophic tissue failure (Burr et al., 1988; Currey, 2002; Sobelman et al., 2004). By reducing the osteon diameter and increasing their concentrations, the efficiency in which transmitted energy is absorbed is also increased (Yeni et al., 1997).

\section{CONCLUSIONS}

Osteopenic changes in long bones that result from longterm immobilization exemplify the important role mechanical loading plays in bone metabolism. Although limited in sample size of individuals experiencing long-term disuse, this study expands our understanding of this relationship with a comprehensive analysis of both macro- and microscopic signatures of functional adaptation and maintenance of the human skeleton. Analyses of the major long bones of individuals experiencing drastic mobility differences have both confirmed previous hypotheses concerning skeletal responses to mechanical loading and shed new light on potential intraskeletal remodeling parameters associated with the strain environment.

Outcomes of this study suggest bones associated with long-term disuse have lower osteon population densities and larger osteon areas, reflecting dramatically lower remodeling rates and reduced strain levels. Regarding bone mass, immobilized skeletal elements demonstrate a reduction in the percentage of cortical area due to endosteal resorption, as predicted by the mechanostat. Differences in bone distribution and the percentage of cortical area present between the long bones of the immobilized individuals and their comparative sample of individuals with normal mobility are observed, particularly within the skeletal elements of the immobilized 70-year old. This observation suggests that bone modeling activity may be insignificant in the unloaded skeleton. A larger sample is required for quantitative statistical analysis, allowing for a more comprehensive study that accounts for a larger range of human variation.

\section{LITERATURE CITED}

Alexandre C, Vico L. 2011. Pathophysiology of bone loss in disuse osteoporosis. Joint Bone Spine 78:572-576.

Birkbeck DP, Failla JM, Hoshaw SJ, Fyhrie DP, Schaffler MB. 1997. The interosseous membrane affects load distribution in the forearm. J Hand Surg 22:975-980.

Bloomfield SA. 1997. Changes in musculoskeletal structure and function with prolonged bed rest. Med Sci Sports Exerc 29:197-206.
Bloomfield SA. 2010. Disuse osteopenia. Curr Osteoporos Rep 8:91-97.

Burr DB. 2010. Cortical bone: a target for fracture prevention? Lancet 375:1672-1673.

Burr DB, Schaffler MB, Frederickson R. 1988. Composition of the cement line and its possible mechanical role as a local interface in human compact bone. J Biomech 21:939-945.

Carter DR. 1984. Mechanical loading histories and cortical bone remodeling. Calcif Tissue Int 36:S19-S24.

Currey JD. 2002. Bones: structure and mechanics. Princeton: Princeton University Press.

Dehority W, Halloran BP, Bikle DD, Curren T, Kostenuik PJ, Wronski TJ, Shen Y, Rabkin B, Bouraoui A, Morey-Holton E. 1999. Bone and hormonal changes induced by skeletal unloading in the mature male rat. Am J Physiol 276:62-69.

Eser P, Frotzler A, Zehnder Y, Wick L, Knecht H, Denoth J, Schiessl H. 2004. Relationship between the duration of paralysis and bone structure: a pQCT study of spinal cord injured individuals. Bone 34:869-880.

Frost HM. 1987. Bone "mass" and the "mechanostat": a proposal. Anat Rec 219:1-9.

Frost HM. 1990. Skeletal structural adaptations to mechanical usage (SATMU): 2. Redefining Wolff's law: the remodeling problem. Anat Rec 226:414-422.

Giangregorio L, Blimkie CJR. 2002. Skeletal adaptations to alterations in weight-bearing activity. Sports Med 32:459-476.

Globus RK, Morey-Holton ER. 2009. Advances in understanding the skeletal biology of spaceflight. Grav Space Biol 22:3-12.

Gross TS, Poliachik SL, Prasad J, Bain SD. 2010. The effect of muscle dysfunction on bone mass and morphology. J Musculoskelet Neuronal Interact 10:25-34.

Iwaniec UT. 1997. Effects of acidity on cortical bone remodeling: a histomorphometric assessment. Madison: University of Wisconsin.

Jaworski ZF, Liskova-Kiar M, Uhthoff HK. 1980. Effect of longterm immobilisation on the pattern of bone loss in older dogs. J Bone Joint Surg 62:104-110.

Kearns AE, Khosla S, Kostenuik P. 2008. Receptor activator of nuclear factor $\kappa \mathrm{B}$ ligand and osteoprotegerin regulation of bone remodeling in health and disease. Endocr Rev 29:155-192.

Lanyon LE. 1984. Functional strain as a determinant for bone remodeling. Calcif Tissue Int 36:56-61.

Qin W, Bauman WA, Cardozo C. 2010. Bone and muscle loss after spinal cord injury: organ interactions. Ann N Y Acad Sci 1211:66-84.

Robling AG, Niziolek PJ, Baldridge LA, Condon KW, Allen MR, Alam I, Mantila SM, Gluhak-Heinrich J, Beliido TM, Harris $\mathrm{SE}$, Turner CH. 2008. Mechanical stimulation of bone in vivo reduces osteocyte expression of sost/sclerostin. J Biol Chem 283:5866-5875.

Robling AG, Stout SD. 2008. Histomorphometry of human cortical bone: applications to age estimation. In: Katzenberg MA, Saunders SR, editors. Biological anthropology of the human skeleton. New York: Wiley-Liss. p149-182.

Schlecht SH. 2012. A histomorphometric analysis of muscular insertion regions: understanding enthesis etiology [Dissertation]. Columbus: The Ohio State University.

Skedros JG, Mason MW, Bloebaum RD. 2001. Modeling and remodeling in a developing artiodactyl calcaneus: a model for evaluating Frost's Mechanostat hypothesis and its corollaries. Anat Rec 263:167-185.

Sobelman OS, Gibeling JC, Stover SM, Hazelwood SJ, Yeh OC, Shelton DR, Martin RB. 2004. Do microcracks decrease or increase fatigue resistance in cortical bone? J Biomech 37:1295-1303.

Stout SD. 1982. The effects of long-term immobilization on the histomorphology of human cortical bone. Calcif Tissue Int 34:337-342.

Sutherland MK, Geoghegan JC, Yu C, Turcott E, Skonier JE, Winkler DG, Latham JA. 2004. Sclerostin promotes the apoptosis of humn osteoblastic cells: a novel regulation of bone formation. Bone 35:828-835.

Troen BR. 2003. Molecular mechanisms underlying osteoclast formation and activation. Exp Gerontol 38:605-614. 
Turner CH. 1999. Site-specific skeletal effects of exercise: importance of interstitial fluid pressure. Bone 24:161-162.

Uhthoff HK, Jaworski ZFG. 1978. Bone loss in response to longterm immobilisation. J Bone Joint Surg 60:420-429.

van Oers RFM, Ruimerman R, Van Rietbergen B, Hilbers PAJ, Huiskes R. 2008. Relating osteon diameter to strain. Bone 43:476-482.

Wakley GK, Portwood JS, Turner RT. 1992. Disuse osteopenia os accompanied by downregulation of gene expression for bone proteins in growing rats. Am J Physiol 263:E1029-E1034.
Wang Q, Whittle M, Cunningham J, Kenwright J. 1996. Fibula and its ligaments in load transmission and ankle joint stability. Clin Orthop Relat Res 330:261-270.

Yeni YN, Brown CU, Wang Z, Norman TL. 1997. The influence of bone morphology on fracture toughness of the human femur and tibia. Bone 21:453-459.

Zebaze RM, Ghasem-Zadeh A, Bohte A, Iuliano-Burns S, Mirams M, Price RI, Mackie EJ, Seeman E. 2010. Intracortical remodelling and porosity in the distal radius and post-mortem femurs of women: a cross-sectional study. Lancet 375:1729-1736. 